\title{
Sugestão de Tratamentos Fitorremediativos Utilizando Aguapé e Moringa Oleífera para os Parâmetros pH e DQO
}

\author{
Arsênio P. V. Neto, Maria N. Silva \& Solange X. Santos
}

O tratamento de efluentes antes de ser lançado aos corpos d'água evita o agravamento do efeito poluidor sobre o ambiente. $\mathrm{O}$ uso de vegetais para a melhoria das condições físico-químicas do meio aquoso é uma técnica muito utilizada e é denominada fitorremediação. Este trabalho teve como objetivo sugerir dois tratamentos fitorremediativos, um utilizando aguapé e outro utilizando moringa para melhoramento das condições físico-químicas do efluente, em relação aos parâmetros pH e DQO. Os resultados de $\mathrm{pH}$ mostraram-se satisfatórios em ambos os casos porém, para o DQO, teve eficiência de $49,64 \%$ no primeiro caso e $17,14 \%$ no segundo.

Palavras-chave: fitorremediação; aguapé; moringa oleífera.

The effluent treatment before being released back to natural bodies of waters prevents the pollution of the environment from escalating. The use of plants to improve the physicochemical conditions of water habitats is a widely used technique and is called phytoremediation. The aim of the present work was directed upon the suggestion of the uses of two separate treatments, one using water hyacinth and another using moringa for improving the physicochemical conditions of the effluent for the parameters $\mathrm{pH}$ and COD. The results showed the $\mathrm{pH}$ values were satisfactory in both cases however, for the COD, efficiency was $49.64 \%$ for the former and $17.14 \%$ for the latter.

Keywords: phytoremediation; water hyacinth; moringa oleifera. 


\section{Introdução}

Na busca do desenvolvimento e de um maior conforto, a humanidade tem avançado sobre os recursos naturais de forma desordenada. Problemas ambientais têm se tornado cada vez mais críticos e frequentes e um dos fatores que proporciona este mal é o aumento da população que acarreta uma crescente produção de alimentos e eliminação da vegetação natural consequentemente aumentando também a poluição ambiental.

Efluentes domésticos, sanitários e industriais, são alguns dos principais fatores poluidores, uma vez que esses dejetos, na maioria dos casos, são lançados em corpos d'água sem o tratamento adequado. As águas de um rio, desta forma, podem se tornar inadequadas ameaçando a saúde da população devido à poluição das águas de abastecimento, dos balneários e dos gêneros alimentícios. Para resolver este problema, é preciso que os efluentes gerados sejam tratados, antes de serem lançados ao meio ambiente. $\mathrm{O}$ tratamento de efluentes tem como intuito, manter os corpos d'água livres de inconvenientes desse gênero ${ }^{1,2}$.

O uso de vegetais para a melhoria das condições físicoquímicas do meio aquoso (fitorremediação) é muito conhecido e aplicado no tratamento de efluentes ${ }^{3}$. Esse é o caso do uso de macrófitas aquáticas que são plantas superiores cujas partes fotossinteticamente ativas estão o tempo todo ou por alguns meses em cada ano, submersas em água ou flutuantes em sua superfície ${ }^{3}$ e da Moringa oleifera.

Eichhornia crassipes, popularmente conhecida como aguapé, é uma macrófita aquática que apresenta pecíolos espessos e um comprimento não maior que $20 \mathrm{~cm}$ o que facilita a flutuação em águas profundas, pode apresentar folhas diferentes em virtude do ambiente em que se encontram, as raízes são escuras e ramificadas, saindo da base da planta e formando um ambiente favorável à reprodução de pequenos peixes ou insetos, muitas vezes fornecendo proteção e/ou alimento, a inflorescência é uma espiga alongada com flores variando de azul claro ao violeta, ou ainda ocasionalmente branco, é pertence à família Pontederiaceae e nativa da América do Sul ${ }^{4,5,6}$.

Sua facilidade de adaptação, somada à sua expressiva assimilação de nutrientes e capacidade de reter elevadas quantidades de íons metálicos fazem dessa planta uma das mais promissoras para o tratamento de efluentes.
O sistema radicular do aguapé funciona como um filtro mecânico, o qual absorve material particulado existente na água, dessa forma, cria um ambiente rico em atividades de bactérias e fungos assumindo a função de um agente de despoluição. Apesar dessas vantagens, em alguns casos a planta é considerada uma "praga" por favorecer a metilação do mercúrio devida a sua alta atividade microbiológica ${ }^{3,7,8,9}$.

Moringa oleifera é uma planta de hábito arbóreo, originária do norte da Índia e comum em regiões tropicais e subtropicais da Ásia, África e América Latina. Ela cresce rapidamente podendo atingir até $12 \mathrm{~m}$, sua casca é cinza e grossa e se parece com cortiça, produz flores de cor creme, vagens triangulares em seção transversal de 30 a $50 \mathrm{~cm}$ e possui sementes aladas ${ }^{10}$.

A moringa pode ser utilizada na clarificação de água para o consumo humano. Uma vez que, em vários países subdesenvolvidos ainda não possuem um tratamento de água adequado, esta se torna uma característica que atribui valor a esta planta ${ }^{11}$. Em Malawi, país da África, observou-se que a água barrenta misturada com o pó das sementes desta planta, resultou em água purificada depois de uma hora, equivalendo ao tratamento de filtração com um coagulante comum para a água como o sulfato de alumínio ${ }^{12}$. Uma das principais características deste coagulante natural é que, além de reduzir 80,0 a 99,5\% da turbidez, é capaz de remover as bactérias na ordem de 90 a $99 \%{ }^{13}$.

Este trabalho teve como objetivo avaliar os parâmetros DQO e pH do tratamento de efluentes realizada com a utilização da aguapé e da moringa oleifera separadente e verificar a adequação para esses parâmetros tendo em vista os padrões estabelecidos por legislações nacionais ${ }^{14}$.

\section{Materiais e Métodos}

O efluente utilizado para as análises físico-químicas deste trabalho é originário da Estação de Tratamento de Efluentes (ETE) da Universidade Estadual de Goiás (UEG), Unidade Universitária de Ciências Exatas e Tecnológicas (UnUCET) e é composto principalmente por resíduos sólidos e líquidos oriundos dos laboratórios químicos e biológicos e por águas residuárias domésticas. As amostras de efluentes foram tratadas fisico-quimicamente quanto aos parâmetros $\mathrm{pH}$ e DQO mediante a metodologia do STANDARD METHODS ${ }^{15}$. 
POTENCIAL HIDROGENIÔNICO (PH) - As medidas foram realizadas utilizando-se um potenciômetro DMPH-2 Digimed, devidamente calibrado com soluções tampão de pH 4,0 e 7,0.

DEMANDA QUÍMICA DE OXIGÊNIO (DQO)

- Realizaram-se as análises de DQO pelo método de refluxo fechado. Para a construção da curva de calibração foram preparados 4 padrões de solução de biftalato de potássio com DQOs equivalentes entre 100 a $500 \mathrm{mg}$ de $\mathrm{O}_{2} \cdot \mathrm{L}^{-1}$.

Para a preparação da amostra, um volume de $2,5 \mathrm{~mL}$ da amostra foi disposto em tubo de ensaio ao qual se adicionou $1,5 \mathrm{~mL}$ da solução digestora. Cuidadosamente foram adicionados $3,5 \mathrm{~mL}$ de ácido sulfúrico reagente, a tampa do tubo foi devidamente apertada e o tubo foi, então, invertido várias vezes, a fim de homogeneizá-las completamente. Após a digestão por 2 horas a temperatura de $150{ }^{\circ} \mathrm{C}$, os tubos foram novamente invertidos por várias vezes. Após o resfriamento foi feita a leitura da absorbância a $600 \mathrm{~nm}$, comparando-se com a curva de calibração e determinou-se a DQO das amostras.

As amostras foram digeridas em digestor tipo Dry Block AL1200 da American Lab.

Todos os experimentos foram conduzidos em triplicata e os dados obtidos correspondem à média aritmética dos três valores obtidos.

\section{ANÁliSE DO TRATAMENTO DE EFLUENTES COM AGUAPÉ}

Amostras de água residuária proveniente da Estação de Tratamento de Efluentes foram coletadas no seguinte ponto:

Ponto 1 - Amostra do efluente bruto, assim que chega à ETE, ou seja, é o efluente antes de qualquer tratamento.

Adicionou-se 3 L desta água residuária em 3 bacias de polietileno de alta densidade com capacidade volumétrica de $5 \mathrm{~L}$, coletou-se amostra desta água antes do tratamento com aguapé (mais ou menos $6 \mathrm{~mL}$ ) e colocou-as em geladeira a $18^{\circ} \mathrm{C}$ para posteriores análises. Após serem selecionadas quanto à uniformidade de tamanho e forma, as plantas foram lavadas em água corrente e posteriormente com água destilada, a fim de remover sujidades e minerais.

Adicionou-se 4 mudas de aguapé em cada bacia de polietileno de alta densidade. O tratamento perdurou- se por 10 dias, sendo que durante esse período não se observou mudanças climáticas consideráveis. No terceiro, quinto, oitavo e décimo dia após a adição da aguapé, colheram-se as amostras de água residuária em tratamento para posteriores análises.

\section{ANÁLISE DO TRATAMENTO DE EFLUENTES COM SEMENTE DE MORINGA}

Utilizou-se, para este tratamento, sementes de moringa previamente armazenadas em garrafas. Foram coletadas amostras de água residuária proveniente da Estação de Tratamento no ponto 1 - Amostra de água antes de qualquer tratamento. Adicionou-se $4 \mathrm{~L}$ de água residuária coletada em 3 bacias de polietileno de alta densidade com capacidade volumétrica de $5 \mathrm{~L}$, colheu-se amostras a as colocaram em geladeira para posteriores análises de $\mathrm{pH}$ e DQO.

Trituraram-se as sementes de moringa oleífera, adicionou-se uma porção de $0,4 \mathrm{~g}$ de sementes trituradas a uma pequena quantidade de água destilada a fim de se obter uma pasta. Transferiu-se esta pasta para uma garrafa PET com auxílio de um funil, adicionou-se 40 $\mathrm{mL}$ de água destilada e agitou-se a garrafa a fim de ativar o poder coagulante das sementes trituradas. Com auxilio de um pedaço de tecido, filtrou-se a solução formada e colocou-se o filtrado na bacia com $4 \mathrm{~L}$ de água residuária. Realizou-se o mesmo processo para a adição dessa pasta nas outras bacias contendo água residuária. Com auxílio de um bastão de vidro misturou-se vagarosamente por 10 a 15 minutos. Após 1 hora colheu-se amostras de cada bacia e armazenou-as em geladeira para posteriores análises de DQO e $\mathrm{pH}$.

Posteriormente, fez-se as análises de DQO e $\mathrm{pH}$ para as amostras colhidas, obtendo-se assim, os dados necessários para ojulgamento da eficácia desse tratamento.

\section{Resultados e Discussão}

\section{TRATAMENTO DE EFLUENTES COM AGUAPÉ}

A temperatura ficou entre 21 e $23{ }^{\circ} \mathrm{C}$ durante todo o tempo de análise. As médias aritméticas das 3 medições dos valores de $\mathrm{pH}$ encontrados no ponto amostral 1 ao longo do tratamento com aguapé foram 7,63; 7,97; 7,64; 7,52 e 7,48 para a água residuária em tratamento antes da adição da aguapé e para o terceiro, quinto, oitavo 
e décimo dia da adição desta respectivamente, como mostrado na Tabela 1 que se segue.

Os resultados de $\mathrm{pH}$ encontrados mostraram que três dias após a adição da aguapé, houve uma pequena elevação, porém nos dias subseqüentes (quinto, oitavo e décimo) estes valores foram diminuindo de modo discreto tendendo à valores neutros. Granato ${ }^{16} \mathrm{em}$ estudos de escala laboratorial, constatou que o aguapé possui um mecanismo de defesa, que ao entrar em soluções alcalinas, alterava o valor de $\mathrm{pH}$ até um valor mais favorável para sua sobrevivência, diminuindo o $\mathrm{pH}$ para valores que tendem à neutralidade. Observou-se isso nos estudos realizados com a queda discreta do $\mathrm{pH}$ se aproximando de 7,0 .

Tabela 1. Valores do $\mathrm{pH}$ dos pontos amostrais 1 durante todo o tratamento com aguapé.

\begin{tabular}{|c|c|c|c|c|c|}
\hline Coleta & $\mathbf{1 a}$ & $\mathbf{2 a}$ & $\mathbf{3 a}$ & $\mathbf{4 a}$ & $\mathbf{5 a}$ \\
\hline \multirow{4}{*}{ Média } & 7,58 & 7,92 & 7,60 & 7,48 & 7,44 \\
\cline { 2 - 6 } & 7,63 & 7,97 & 7,65 & 7,52 & 7,49 \\
\cline { 2 - 6 } & 7,67 & 8,01 & 7,67 & 7,57 & 7,51 \\
\cline { 2 - 6 } & $\begin{array}{c}7,63 \\
( \pm 0,045)\end{array}$ & $\begin{array}{c}7,97 \\
( \pm 0,045)\end{array}$ & $\begin{array}{c}7,64 \\
( \pm 0,036)\end{array}$ & $\begin{array}{c}7,52 \\
( \pm 0,045)\end{array}$ & $\begin{array}{c}7,48 \\
( \pm 0,036)\end{array}$ \\
\hline
\end{tabular}

Este tratamento, realizado em laboratório, também demonstrou valores de $\mathrm{pH}$ permitidos ao lançamento de efluentes nos corpo d'água ${ }^{14}$. A Tabela 2 mostra os valores das médias aritméticas das 3 medições de DQO do ponto amostral 1 que foram 463,33; 453,33; 426,67; 240,$00 ; 233,33$ para a água residuária em tratamento antes da adição da aguapé e para o terceiro, quinto, oitavo e décimo dia da adição desta respectivamente.

Tabela 2. Valores de absorbância e DQO no tratamento com aguapé.

\begin{tabular}{|c|c|c|}
\hline Coletas & Absorbância & DQO \\
\hline $1^{\mathrm{a}}$ & 0,136 & 463,33 \\
\hline $2^{\mathrm{a}}$ & 0,133 & 453,33 \\
\hline $3^{\mathrm{a}}$ & 0,071 & 246,67 \\
\hline $4^{\mathrm{a}}$ & 0,069 & 240,00 \\
\hline $5^{\mathrm{a}}$ & 0,067 & 233,33 \\
\hline
\end{tabular}

Pelos resultados encontrados no DQO, verificouse uma pequena queda entre o primeiro e o terceiro dia (primeira e segunda coleta), isso se esclarece pela acomodação da aguapé na água, e do terceiro para o quinto dia (segunda e terceira coleta) houve uma diminuição bem elevada pelo fato da macrófita já estar acondicionanda na água de esgoto fazendo o seu trabalho de limpeza e do quinto para o oitavo e décimo dia (terceira, quarta e quinta coleta) percebeu-se que a macrófita já havia terminado o seu trabalho no tratamento praticamente mantendo o mesmo valor de DQO.

Nota-se que houve uma eficiência da referida macrófita, retendo a matéria orgânica e liberando a quantidade necessária de oxigênio para a água tratada, diminuindo em 49,64 \% o valor de DQO inicial. França et. $a l .{ }^{17}$, em seu trabalho, obteve uma taxa de remoção de $53,37 \%$ no valor de DQO no tratamento de efluentes domésticos utilizando aguapé cultivada em caixas de polietileno e $28,45 \%$ utilizando a macrófita em questão cultivada em caixas de amianto.

\section{TRATAMENTO DE EFLUENTES COM SEMENTE DE MORINGA}

A tabela 3 mostra os valores de $\mathrm{pH}$ encontrados antes e depois do tratamento com semente de moringa oleífera e a média aritmética desses valores que são respectivamente 7,94 e 7,34 , na qual a temperatura medida foi de $22^{\circ} \mathrm{C}$.

Tabela 3. Valores de $\mathrm{pH}$ encontrados antes e depois o tratamento com semente de moringa oleífera.

\begin{tabular}{|c|c|c|}
\hline \multirow{2}{*}{ Repetição } & \multicolumn{2}{|c|}{ Valores de $\mathbf{p H}$} \\
\cline { 2 - 3 } & Inicial & Final \\
\hline 1 & 7,88 & 7,43 \\
\hline 2 & 8,01 & 7,32 \\
\hline 3 & 7,92 & 7,35 \\
\hline Média & $7,94( \pm 0,066)$ & $7,37( \pm 0,057)$ \\
\hline
\end{tabular}

Percebe-se a queda de $\mathrm{pH}$ com a tendência a neutralidade $(8,01-7,32)$ e que os valores antes e depois se enquadram na faixa permitida. Rico et. al. ${ }^{18}$, utilizaram 8 g.L $\mathrm{L}^{-1}$ da semente de moringa para $15 \mathrm{~mL}$ de água residuária de curtume para o tratamento desta mantendo o $\mathrm{pH}=8$ e observaram que os valores de $\mathrm{pH}$ não sofreram alterações significativas após a adição de semente, provocando apenas uma leve diminuição desses valores. Este fato de não alterar significamente o $\mathrm{pH}$ e a alcalinidade da água torna-se uma vantagem 
a este método em relação ao método de coagulação utilizando alumínio.

A tabela 4 mostra os valores de absorbância e DQO encontrados antes e depois do tratamento com semente de moringa oleífera. Nota-se que o valor de DQO teve uma pequena queda após o tratamento com semente de moringa.

Tabela 4. Valores de absorbância e DQO antes e depois tratamento com semente de moringa oleífera.

\begin{tabular}{|c|c|c|}
\hline & Absorbância & DQO \\
\hline Inicial & 0,103 & 352,22 \\
\hline Final & 0,086 & 295,55 \\
\hline
\end{tabular}

A diminuição do valor de $\mathrm{DQO}$ em relação ao valor inicial para esse tratamento é de $17,14 \%$. Rico et. al. ${ }^{18}$ no tratamento de água residuária de curtume utilizando moringa oleifera relatou um aumento no DQO, justificouse o ocorrido pelo fato da moringa oleifera ser composta de material orgânico formado por polissacarídeos. A não concordância com este trabalho pode ser explicada pela baixa quantidade de semente de moringa adicionada na água a ser tratada e pelo tempo de contato da água residuária com a semente, uma vez que os trabalhos seguiram metodologias diferentes.

\section{Conclusões}

O tratamento com aguapé teve uma diminuição de DQO considerável de 49,64\% e valores de $\mathrm{pH}$ dentro do permitido $^{14}$, mostrando-se muito eficiente. Além dos bons resultados que melhoram a qualidade da água para despejo dando prioridade ao meio ambiente, a implementação de lagoas de aguapé é uma boa sugestão para o tratamento de efluentes por possuírem como vantagem o fato de serem de baixo custo e de simples operação de manutenção ${ }^{19}$ além de crescer com grau de aceleração altíssimo. Já o tratamento com taboa apesar de manter o $\mathrm{pH}$ na faixa permitida, não é eficaz para esse sistema por diminuir muito pouco o valor de DQO inicial, mostrando ser um bom coagulante sendo muito utilizada para o melhoramento da qualidade da água pra consumo próprio mas não para tratamento de efluentes uma vez que tende a diminuir a quantidade de oxigênio disponível para espécies vivas aquáticas.

\section{Referências Bibliográficas}

1. Greenway, M. Ecological Engineering, 2005, 25, 501.

2. Kunz, A., et. al. Química Nova, 2002, 25, 78.

3. Andrade, C. M., Tavares, S. R. L., Mahler, C. F. Fitorremediação: O uso de plantas na melhoria da qualidade ambiental. Editora Oficina de Textos, São Paulo - SP, 2007, $1^{\circ}$ Ed.

4. Souza, J. B. de. Avaliação do potencial de macrófitas aquáticas na biorremediação de uma lagoa de estabilização biológica de efluente doméstico no município de Minaçu, Goiás. Universidade Estadual de Goiás, Anápolis - GO, 2008.

5. Joly, A. B. Botânica: Introdução à taxonomia vegetal. Editora Nacional, São Paulo - SP, 2002, $2^{\circ}$ Ed.

6. Lima, C. C. A.; Silva, L. J. da; Castro, W. S. Morfologia Externa Vegetal. Instituto de Biologia - Universidade Federal de Uberlândia, Uberlândia - MG, 2006.

7. Oliveira, J. A., et. al. Rev. Bras. Fisiol. Veg., 2001, 13, 329.

8. Ballem, A. et. al. XXXI Congresso Brasileiro de Ciência do Solo - Conquistas \& Desafios da Ciência do Solo Brasileiro, 2007, Gramado- RS.

9. Mauro, J. B. N.; Guimarães, J. R. D. Aguapé agrava contaminação por mercúrio. Ciência Hoje, 1999, 35, 68.

10. HDRA - The Organic organization. Moringa oleifera: A multipurpose tree. 2002, HDRA Publishing.

11. Miranda, J. R. P. et. al. Ver. Bras. Ci. Solo, 2002, 26, 957.

12. Yongabi, K. A. FMENV/ZERI Research centre, 2003. 72, 1.

13. Muyibi, S. A.; Evison, L. M. Water research, 1995, 29, 1099.

14. CONAMA: Resolução $n^{\circ} 357 / 2005$.

15. AMERICAN PUBLIC HEALTH ASSOCIATION. Standart Methods for the Examination of Water and Wastewater, 1998, $20^{\circ}$ ed. Washington - D.C.

16. Granato, M. CETEM/CNPQ, 1995, 5, 39.

17. França. J. B. A. et. al. Revista Engenharia da Agricultura, 2012, $20,554$.

18. Rico, T. E. F. et. al. Revista Agro@mbiental on-line, 2010, 4, 96.

19. El-Shafai, S. A. et. al. Bioresource Technology, 2007, 98, 798.

\section{Arsênio P. V. Neto*, Maria N. Silva \& Solange $X$. Santos}

Universidade Estadual de Goiás, Unidade Universitária de Ciências Exatas e Tecnológicas, $\mathrm{Br}$ 153, Km 98, Anápolis/GO, Brasil.

*e-mail: apvn5@hotmail.com 